Revista Brasileira de Agricultura Irrigada v.12, nº.3, p. 2570 - 2578, 2018 ISSN 1982-7679 (On-line)

Fortaleza, CE, INOVAGRI - http://www.inovagri.org.br

DOI: 10.7127/rbai.v12n300697

Protocolo 697.18 - 08/06/2017 Aprovado em 22/05/2018

\title{
SALINIDADE DA SOLUÇÃO NUTRITIVA NA PRODUÇÃO DE ALFACE AMERICANA EM SISTEMA HIDROPÔNICO NFT
}

\author{
Janardann Moisés Patrício Fernandes ${ }^{1}$, Artur Leônio Maia Fernandes ${ }^{2}$, Nildo da Silva Dias ${ }^{3}$, \\ Christiano Rebouças Cosme ${ }^{4}$, Luan Vítor Nascimento ${ }^{5}$, Italo Sorac Rafael de Queiroz ${ }^{6}$
}

\section{RESUMO}

O presente estudo foi conduzido com o propósito de avaliar o crescimento e a produtividade da alface Americana cultivada em sistema hidropônico NFT com diferentes concentrações salina da solução nutritiva. $\mathrm{O}$ ensaio experimental foi conduzido em ambiente protegido na Universidade Federal Rural do Semi-Árido (UFERSA) em Mossoró, RN. O delineamento experimental foi o de blocos casualizados, sendo cinco tratamentos e quatro repetições. Os tratamentos consistiram de cinco níveis de salinidade obtidos pela variação da solução nutritiva padrão para a cultura da alface $\left(1,28 ; 1,78 ; 2,25 ; 2,75\right.$ e 3,24 dS m $\left.{ }^{-1}\right)$. Foram avaliados o diâmetro do caule, a matéria fresca da parte aérea, o diâmetro da parte aérea, o número de folhas e a área foliar das plantas de alface. Os resultados mostram que, soluções nutritivas de até $55 \%$ da solução nutritiva padrão não reduziram o crescimento e a produção da alface Americana. Os efeitos do aumento da concentração da solução nutritiva são mais severos sob a massa fresca da parte aérea da alface Americana cultivada em sistema hidropônico NFT.

Palavras-chave: Lactuca sativa L, cultivo sem solo, nutrição mineral.

\section{NUTRIENT SOLUTION SALINITY ON AMERICAN LETTUCE YIELD IN NFT HYDROPONIC SYSTEM}

\footnotetext{
${ }^{1}$ Graduado em Agronomia, Universidade Federal Rural do Semi-Árido, Mossoró, Brasil. janardann@hotmail.com

2 Especialista em Metodologia do Ensino na Educação Superior, Centro Universitário Internacional, arthurleonio_2012@hotmail.com

${ }^{3}$ Professor Associado III, Centro de Ciências Agrárias, Departamento de Ciências Agronômicas e Florestais, Universidade Federal Rural do Semi-Árido, Mossoró, Brasil.nildo@ufersa.edu.br

${ }^{4}$ Professor Adjunto II, Centro de Engenharias, Departamento de Engenharia e Ciências Ambientais, Universidade Federal Rural do Semi-Árido, Mossoró, Brasil. christianoreboucas@hotmail.com

${ }^{5}$ Graduando em Agronomia, Universidade Federal Rural do Semi-Árido, Mossoró, Brasil.

lvitornascimento@gmail.com

${ }^{6}$ Doutorando em Manejo de Solo e Água, Universidade Federal Rural do Semi-Árido, Mossoró, Brasil.

italosorac@hotmail.com
} 


\title{
Fernandes et al.
}

\begin{abstract}
The present study was designed to test growth and yields of American lettuce plants cultivated on nutrient film technique (NFT) under different levels of nutrient solution salinity. The experiment was carried out in greenhouse at Federal University Rural do Semi-Árido (UFERSA), Mossoró, Rio Grande do Norte state, Brazil. The experimental design was a randomized block design, with five treatments and four replications. The treatments consisted of five salinity levels obtained by varying the concentration from standard nutrient solution to lettuce crop $(1.28,1.78,2.25,2.75$ and $3.24 \mathrm{dS} \mathrm{m}^{-1}$ ). The parameters stem diameter, shoots fresh matter, shoot diameter, number of leaves and leaf area of lettuce plant were analyzed. Results showed that nutrient solution up to 55\% of concentration from standard solution did not reduce growth and yield lettuce. The effects of increasing of salt into nutrient solution were more severe on shoots fresh matter of the lettuce plant cultivated by hydroponic system NFT.
\end{abstract}

Keywords: Lactuca sativa L, hydroponics, mineral nutrition.

\section{INTRODUÇÃO}

A alface (Lactuca sativa L.) é a hortaliça folhosa mais consumida no mundo e, o seu cultivo em sistema hidropônico NFT (Nutrient Film Technique) sob ambiente protegido tem crescido em regiões áridas e semiáridas, principalmente, devido à fácil adaptação da cultura que resulta em maiores rendimentos com maior eficiência do uso da água e redução do ciclo produtivo em relação aos cultivos tradicionais (OHSE et al., 2001; SILVA et al., 2010).

Entretanto, a produção satisfatória da alface em cultivo hidropônico depende essencialmente da qualidade da solução nutritiva fornecida, principalmente no que se refere ao $\mathrm{pH}$, a temperatura e a composição salina (teor, concentração e tipos de sais) (DOMINGUES et al., 2012).

Muitas fórmulas de soluções nutritivas têm sido usadas e avaliadas quanto à produtividade das hortaliças em sistema hidropônico, porém, elevadas concentrações salinas da solução nutritiva em condições de altas temperaturas, umidade e luminosidade como, como as que ocorrem no estado do Rio de Grande do Norte, têm provocado situações inusitadas que não ocorrem normalmente em clima temperado. Dentre elas, distúrbios fisiológicos nas plantas podem ser considerados como os mais preocupantes, expressando-se na forma de murcha excessiva nas horas mais quentes do dia, queima das bordas das folhas e perda na produtividade. Além disso, a alta salinidade da solução nutritiva, o crescimento, a expansão da superfície foliar e o metabolismo do carbono primário de muitas culturas são afetados negativamente devido ao efeito osmótico, déficit hídrico, toxicidade de íons e desequilíbrio nutricional (DE PASCALE et al., 2013).

É crescente a preocupação em reduzir a concentração das soluções nutritivas, por vários motivos, os quais são: redução do teor de nitrato nos tecidos vegetais, diminuição do potencial de eutroficação das soluções remanescentes dos cultivos hidropônicos e, redução dos custos de produção por meio do aumento da eficiência do uso do nutriente (TURAZI et. al., 2006).

Diante do exposto, objetivou-se com este trabalho avaliar o crescimento e a produtividade da alface Americana cultivada em sistema hidropônico NFT com diferentes concentrações salina da solução nutritiva sob condições protegidas.

\section{MATERIAL E MÉTODOS}

O experimento foi realizado em ambiente protegido tipo capela (estufa plástica) no Departamento de Ciências Ambientais e 


\section{SALINIDADE DA SOLUÇÃO NUTRITIVA NA PRODUÇÃO DE ALFACE AMERICANA EM SISTEMA HIDROPÔNICO NFT}

Tecnológicas da Universidade Federal Rural do Semi-Árido (UFERSA), Mossoró (51' S, $37^{\circ}$ 20' W e $18 \mathrm{~m}$ ).

O clima da região, segundo classificação de Köppen, é do tipo BSwh', ou seja, quente com estação chuvosa no verão, atrasando-se para o outono. A precipitação média anual é de $825 \mathrm{~mm}$, sendo março e abril os meses mais chuvosos. A temperatura média anual é de $27,4^{\circ} \mathrm{C}$, com média das máximas igual a $33,3^{\circ} \mathrm{C}$ e das mínimas $22,6^{\circ} \mathrm{C}$, a insolação média é de $236 \mathrm{~h}$ mensais e a umidade relativa média é de 68,9\% (CARMO FILHO; OLIVEIRA, 1989).
Os tratamentos foram constituídos por cinco níveis de salinidade da solução nutritiva para a cultura da alface $(1,28 ; 1,78 ; 2,25 ; 2,75$ e 3,24 dS m $\mathrm{m}^{-1}$ ) obtidas de acréscimos de $\mathrm{NaCl}$ e diluições da solução nutritiva padrão recomendada por FURLANI et al. (1999) (25, 50, 75, 100 e 125\%, respectivamente) para climas de influência subtropicais. As soluções nutritivas utilizadas no experimento foram preparadas com água de abastecimento acrescidos dos sais fertilizantes de acordo com as concentrações dos nutrientes em cada nível de salinidade da solução nutritiva (Tabela 1).

Tabela 1. Composição de sais da solução nutritiva em função do acréscimo de sais e diluição da solução padrão.

\begin{tabular}{crrrrrrr}
\hline Solução padrão & \multicolumn{7}{c}{ Concentração (mg L ${ }^{-1}$ ) } \\
\cline { 2 - 8 }$(\%)$ & ${\mathrm{N}-\mathrm{NO}_{3}{ }^{-}}{\mathrm{N}-\mathrm{NH}_{4}{ }^{+}}$ & $\mathrm{P}$ & $\mathrm{K}$ & $\mathrm{Ca}$ & $\mathrm{Mg}$ & $\mathrm{S}$ \\
\hline 125 & 217,5 & 30,0 & 48,7 & 228,7 & 177,5 & 47,5 & 65,0 \\
100 & 174,0 & 24,0 & 39,0 & 183,0 & 142,0 & 38,0 & 52,0 \\
75 & 130,5 & 18,0 & 29,2 & 137,2 & 106,5 & 28,5 & 39,0 \\
50 & 87,0 & 12,0 & 19,5 & 91,5 & 71,0 & 19,0 & 26,0 \\
25 & 43,5 & 6,0 & 9,7 & 45,7 & 35,5 & 9,5 & 13,0 \\
\hline
\end{tabular}

Os micronutrientes foram mantidos na mesma concentração em todos os tratamentos: B $=0,3, \mathrm{Cu}=0,02, \mathrm{Fe}=2, \mathrm{Mn}=0,4, \mathrm{Mo}=0,06 \mathrm{e}$ $\mathrm{Zn}=0,06 \mathrm{mg} \mathrm{L}^{-1}$. As soluções de macronutrientes foram preparadas a partir de sais comerciais indicados para fertirrigação (nitrato de potássio, nitrato de cálcio, fosfato monoamônio e sulfato de magnésio) e, para os micronutrientes foram utilizados sais puros.

Cada parcela experimental foi constituída por uma canaleta de PVC, sobre traves de madeira a $1 \mathrm{~m}$ de altura, espaçadas de $0,20 \mathrm{~m}$ entre plantas e $0,30 \mathrm{~m}$ entre canaletas, tendo o orifício de alocação das mudas com 0,09 m de diâmetro. Cada tratamento foi representado por um sistema hidropônico NFT, composto basicamente por um tanque com capacidade de 150 L de solução nutritiva, um sistema de bombeamento, quatro canaletas de cultivo e um sistema de retorno ao tanque.

O delineamento estatístico adotado foi o de blocos casualizados com quatro repetições, sendo cada bloco composto por cinco tratamentos.

A solução nutritiva era bombeada às canaletas e escoava por gravidade, formando uma fina lâmina de solução que irrigava as raízes. $\mathrm{O}$ acionamento do sistema de bombeamento era controlado por timer, ligando e desligando o sistema, a cada 15 minutos durante o dia, permanecendo desligado durante a noite. As canaletas de cultivos da bancada de produção tinham capacidade para 16 mudas, cada bancada possuía cinco canaletas (tratamentos) conectados a cinco diferentes reservatórios de abastecimento automático.

O plantio da alface Americana foi feito em bandejas de isopor com 128 células preenchidas com substrato de fibra de coco. O transplante foi realizado aos 23 dias após o plantio, quando as plantas apresentaram de 5 a $6 \mathrm{~cm}$ de altura e cinco folhas (incluindo os cotilédones), com emissão da sexta. Para cada tratamento, diariamente foram feitas medições da 
condutividade elétrica e do $\mathrm{pH}$ da solução nutritiva com auxílio de um condutivímetro e um pHmetro, respectivamente.

A colheita foi realizada aos 30 dias após o transplantio (DAT) para a realização das variáveis de crescimento e produção: diâmetro caulinar (DC), estimado com paquímetro digital; número de folhas (NF), determinado pela contagem de folhas verdes maiores de $3,0 \mathrm{~cm}$ de comprimento, desprezando-se as amareladas e/ou secas, partindo-se das folhas basais até a última folha aberta; matéria fresca da parte aérea (MFPA), estimada por pesagem em balança digital de precisão; e área foliar (AF), utilizando o integrador de área foliar, modelo LI-3100 da Licor.

Os resultados das variáveis avaliadas foram interpretados individualmente por meio da análise de variância. O fator quantitativo relativo aos níveis de salinidade foi analisado estatisticamente por meio de regressão polinomial linear e quadrática.

\section{RESULTADOS E DISCUSSÃO}

As concentrações das soluções nutritivas aplicadas no cultivo da alface em NFT influenciaram significativamente $(\mathrm{p} \leq 0,01)$ as variáveis de crescimento e produção, exceto o número de folhas (NF).

Houve efeito quadrático da matéria fresca da parte aérea (MFPA) da alface em função da $\mathrm{CE}$ da solução nutritiva $(\mathrm{p} \leq 0,05)$, sendo registrado um incremento da matéria fresca da parte aérea até a salinidade da solução nutritiva de 1,97 dS m ${ }^{-1}$ (Figura 1), correspondendo a uma diluição na composição dos sais da solução nutritiva padrão de, aproximadamente, 55\% e, matéria fresca da parte aérea máxima da alface Americana na ordem de 136,5 g planta ${ }^{-1}$, aproximando-se do peso médio comercial encontrado por Ferreira et al. (2009) quando avaliaram as cultivares Simpson, Marisa e Vera em sistema hidropônico de cultivo (163,43, 171,06 e 141,61 g planta ${ }^{-1}$, respectivamente).

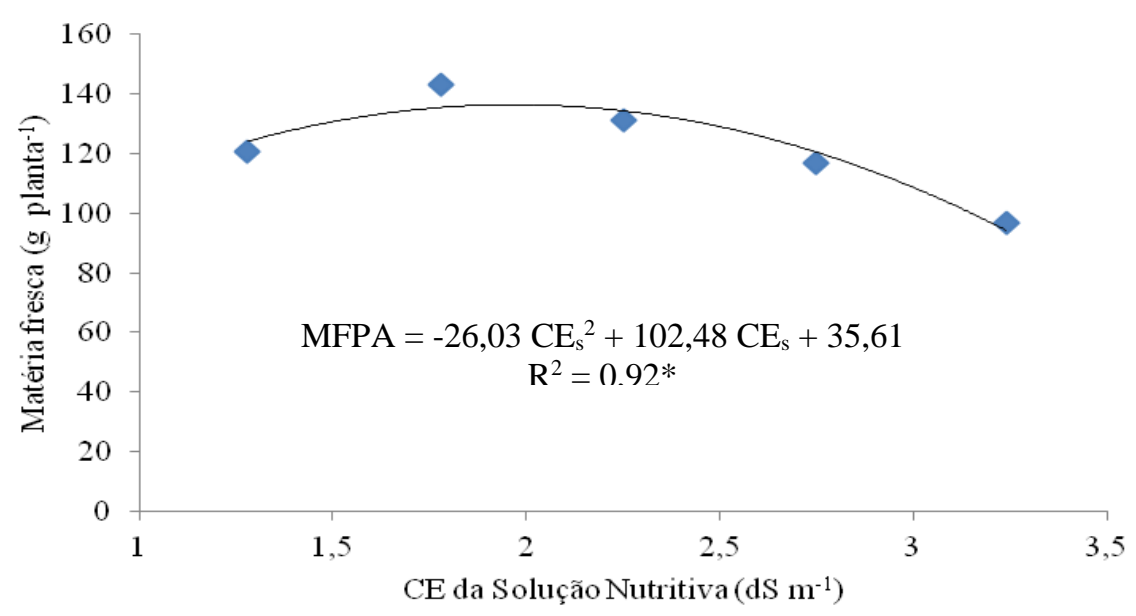

Figura 1. Matéria fresca da parte aérea em função da salinidade da solução nutritiva da alface americana cultivada em hidroponia NFT sob condições protegidas.

Entretanto, é válido acrescentar que a salinidade normalmente afeta mais a produção comercial que a total da alface Americana, uma vez que a maioria das folhas produzidas não participam da formação da sua cabeça (GERVÁSIO et al., 2000).

Dias et al. (2011) encontraram reduções significativas na massa de matéria fresca da parte aérea em duas cultivares de alface (Babá de verão e Verônica) em sistema hidropônico utilizando solução nutritiva preparada com rejeito salino.

Com relação ao diâmetro da parte aérea da alface, verificou-se um efeito quadrático crescente $(p \leq 0,05)$ em função do incremento da 


\section{HIDROPÔNICO NFT}

CE da solução nutritiva hidropônica, sendo registrado ponto de máxima para o diâmetro igual a 27,62 $\mathrm{cm}\left(\mathrm{CEs}_{\mathrm{s}}=2,43 \mathrm{dS} \mathrm{m}^{-1}\right)$ (Figura 2). Deste modo, pode-se inferir que os efeitos da salinidade da solução nutritiva são mais severos sob a matéria fresca do que o diâmetro da parte aérea da alface americana, uma vez que o ponto de máximo diâmetro foi obtido com a diluição de 68\% da composição dos sais da solução nutritiva padrão, ou seja, uma maior CE da solução.

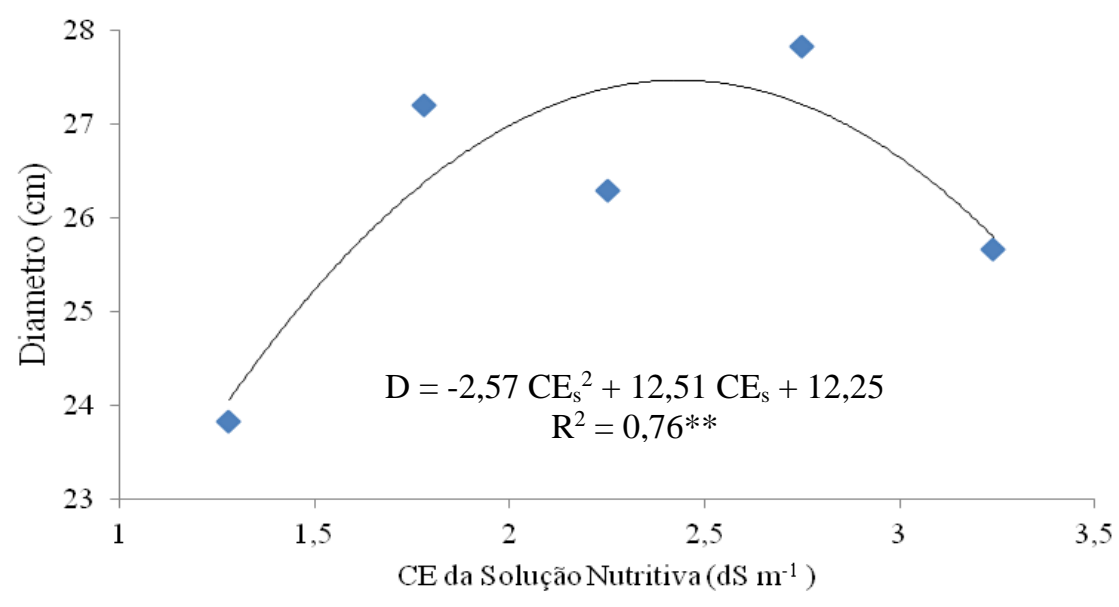

Figura 2. Diâmetro da parte aérea da alface americana cultivada em hidroponia NFT em função da salinidade da solução nutritiva.

Os resultados do presente estudo foram semelhantes aos encontrados por Costa et al. (2001), os quais obtiveram efeitos quadráticos para as variáveis diâmetro da parte aérea da alface americana (cultivar Ryder) em função do incremento da solução nutritiva em sistema hidropônico.

O número de folhas da alface decresceu linearmente ( $\mathrm{p} \leq 0,01)$ com o incremento da CE na solução nutritiva (Figura 3). Vários autores reportam os efeitos da salinidade sobre o crescimento e desenvolvimento da alface (DANTAS et al., 2010 e MORAES et al., 2014), mas não fazem referência ao efeito dos sais sobre a emissão de folhas, apenas reportam à redução de fitomassa da parte aérea, levando a crer que tenha havido também redução do número de folhas com o incremento da salinidade da solução nutritiva. 
Fernandes et al.

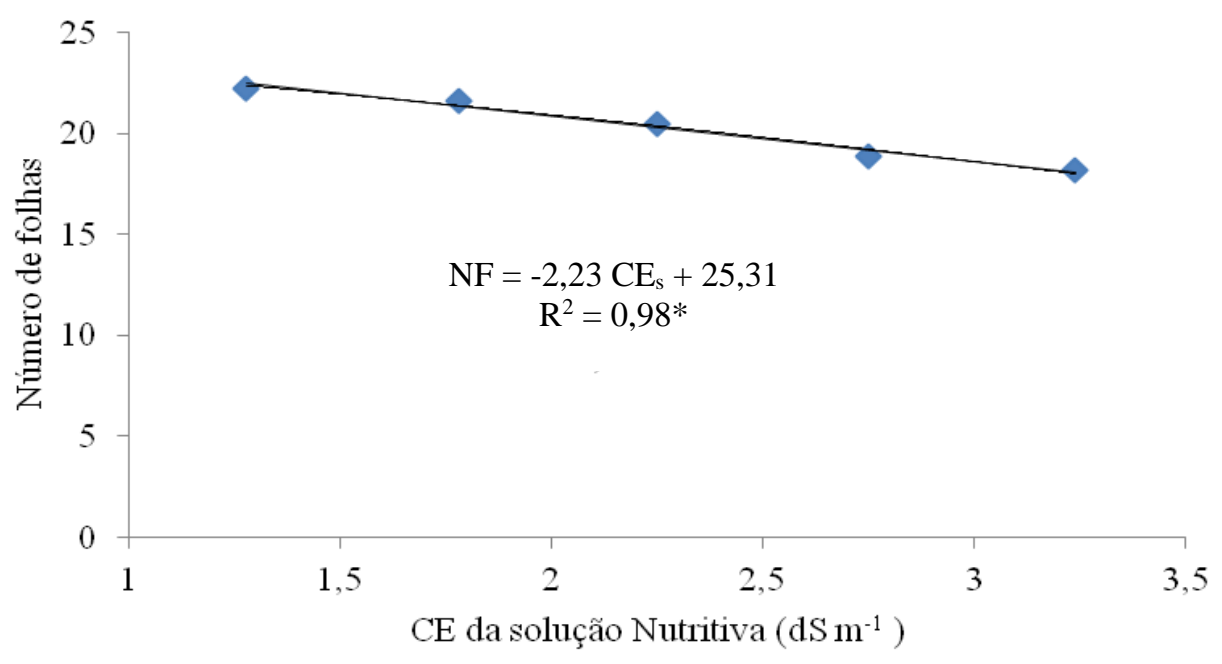

Figura 3. Número de tolhas da altace americana cultivada em hidroponia NF゙I' em tunção da salinidade da solução nutritiva.

Miceli et al. (2003) estudaram os efeitos da salinidade da solução nutritiva causada por cloreto do sódio em hidroponia com substrato de fibra de coco em duas cultivares de alface (Sicília Severus e Ballerina) e concluíram que há redução linear no número de folhas em função do aumento da CE da solução. Viana et al. (2001), avaliaram os efeitos do estresse salino em sistema tradicional de cultivo da alface e, encontraram expressiva redução do número de folhas em função do incremento da salinidade da água de irrigação (perdas acima de $10 \%$ por dS $\left.\mathrm{m}^{-1}\right)$.
A redução do número de folhas em condições de estresse salino é uma adaptação das plantas para manter a absorção de água, sendo consequência de alterações morfológicas e anatômicas nas plantas, refletindo-se na perda de transpiração para manter a absorção de água.

A Figura 4 apresenta os resultados de área foliar em função da salinidade da solução nutritiva, sendo verificado efeito quadrático crescente $(p \leq 0,05)$. O aumento unitário CEs foi claramente o motivo da redução na área foliar das plantas, comprovando a sensibilidade da alface a determinados níveis de salinidade.

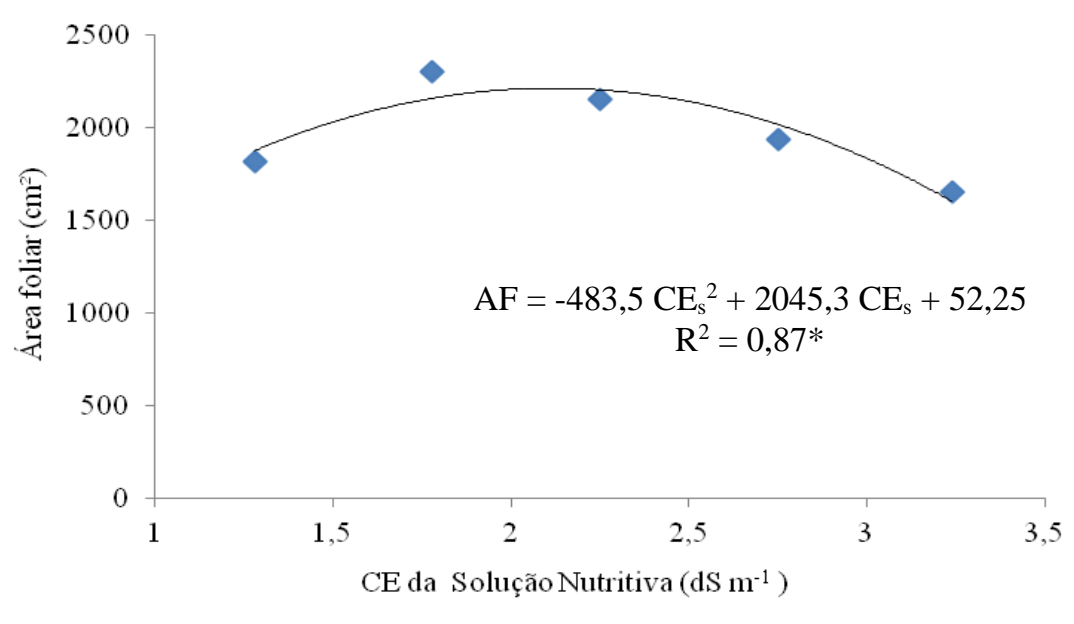

Figura 4. Área foliar da alface Americana cultivada em hidroponia NFT em função da salinidade da solução nutritiva. 


\section{SALINIDADE DA SOLUÇÃO NUTRITIVA NA PRODUÇÃO DE ALFACE AMERICANA EM SISTEMA HIDROPÔNICO NFT}

O decréscimo da área foliar provavelmente decorre da diminuição do volume de células (TAIZ; ZEIGER, 2004) e, segundo Mittova et al. (2002), as reduções de área foliar e de fotossíntese contribuem, de certo modo, para adaptação da cultura à salinidade. A redução da área foliar sob estresse hídrico pode ser um mecanismo de sobrevivência que permite a conservação de água, pela menor área transpiratória das plantas. Sob condições de deficiência hídrica induzida pelo efeito osmótico (seca fisiológica) são comuns alterações morfológicas e anatômicas nas plantas como medida de manter a absorção de água e reduzir a taxa de transpiração. Dentre as mudanças morfológicas destaca-se a redução do tamanho e do número de folhas, como constatado nesse estudo.

De um modo geral, a variação positiva ou negativa da produtividade da alface americana no que se refere à matéria fresca, está relacionada ao incremento ou redução da CEs. A cultura da alface americana respondeu bem ao incremento da salinidade da solução nutritiva quando preparada com água de abastecimento, uma vez que a fonte hídrica é de boa qualidade. Entretanto, quando se dispõe apenas de água salina, a condutividade elétrica da água da solução nutritiva deve ser considerada como o principal fator de restrição da produção (KIM et al., 2016), uma vez que seus efeitos de toxicidade e osmótico são mais severos do que os causados pelo excesso de fertilizantes utilizados na composição da solução nutritiva.

Além disso, deve-se ressaltar que em cultivos tradicionais em campo aberto, há reduções na tolerância das culturas à salinidade em relação aos cultivos hidropônicos devido, principalmente, aos efeitos da matriz do solo somados aos efeitos osmóticos sob a redução da absorção de água pelas plantas (SANTOS et al., 2010; DIAS et al., 2011; SILVA et al., 2016). Em cultivos em solos de textura média, Ayers \& Westcot (1999) concluíram que, quando a concentração salina do meio apresenta CE entre 1,3 e 3,0 dS m ${ }^{-1}$, a alface não se desenvolve e nem produz com viabilidade econômica. Discordando desses resultados, Soares et al. (2007) obtiveram produtividade comercial da alface com CEs de até 4,03 $\mathrm{dSm}^{-1}$ em sistema hidropônico NFT.

\section{CONCLUSÕES}

O uso de 55\% da composição da solução nutritiva padrão recomendada para as regiões de climas subtropicais do Brasil potencializa a produção de matéria fresca de alface americana em sistema hidropônico NFT em condições protegidas.

Os efeitos da salinidade da solução nutritiva hidropônica para a cultura da alface são mais severos sob a produção de matéria fresca da parte aérea do que as demais variáveis estudadas.

\section{REFERÊNCIAS}

AYERS, R. S.; WESTCOT, D. W. 1999. A qualidade da água na agricultura. Tradução de Gheyi, H. R., Medeiros, J. F. \& Damasceno, F. A. V. 2.ed. Campina Grande: UFPB. 153p. (Estudos FAO Irrigação e Drenagem, 29).

CARMO FILHO, F. do; OLIVEIRA, O. F. de. Mossoró: um município do semi-árido nordestino - características climáticas e aspectos florísticos. Mossoró: Coleção Mossoroense, 1989. 62p.

COSTA, P. C.; BIDONE, E. B.; SESSO, T. M.; CAÑIZARES, K. A. L.; GOTO, R. Condutividade elétrica da solução nutritiva e produção de alface em hidroponia. Scientia Agrícola, v.58, n.3, p. 595-597, 2001.

DANTAS, D. C.; SANTOS, R. S. S.; NOGUEIRA, F. P.; DIAS, N. S.; FERREIRA NETO, M. 2010. Utilização de águas salobras no cultivo hidropônico da alface. Irriga, v.15, p.111-118, 2010. 
DE PASCALE, S.; ORSINI, F.; PARDOSSI, A. Irrigation water quality for greenhouse horticulture. In Good Agricultural Practices for Greenhouse Vegetable Crops; FAO Plant Production and Protection Paper 217; Food and Agriculture Organization of the United Nations: Rome, Italy, 2013; p. 169-204.

DIAS, N. S.; LIMA, F.A.;SILVA, C. R.;SOUSA NETO, O. N.;CHEYI, H. R.2011a.Use of reject brine from desalination on different development stages of hydroponic lettuce. Revista Caatinga, v.24, n.1, p.76-81, 2011.

DOMINGUES, D. S.; TAKAHASHI, H. W.; CAMARA, C. A. P.; NIXDORF, S. L. Automated system developed to control $\mathrm{pH}$ and concentration of nutrient solution evaluated in hydroponic lettuce production. Computers and Electronics in Agriculture, v.84, p.53-61, 2012.

FERREIRA, R. L. F.; NETO, S. E. A.; SILVA, S. S.; ABUD, E. A.; REZENDE, M. I. F. L.; KUSDRA, J. L. Combinações entre cultivares, ambientes, preparo e cobertura do solo em características agronômicas de alface. Horticultura Brasileira, v.27, n.3, 2009.

FURLANI, P. R.; SILVEIRA, L. C. P.; BOLONHEZI, D.; FAQUIN, V. 1999. Cultivo hidropônico de plantas. Campinas: Instituto Agronômico. 52p. (Boletim Técnico, 180).

GERVÁSIO, E. S.; CARVALHO, J. A.; SANTANA, M. J. Efeito da salinidade da água de irrigação na produção da alface americana. Revista Brasileira de Engenharia Agrícola e Ambiental, Campina Grande, v.4, n.1, p.125128, 2000.

KIM, H.; JEONG, H.; JEON, J.; BAE, S. Effects of Irrigation with SalineWater on Crop Growth and Yield in Greenhouse Cultivation. Water, V.6, n.127, 2016

MICELI, A.; MONCADA A.; D'ANNA F.
Effect of salt stress in lettuce cultivation. Acta Horticulturae, v.609, p.371-375, 2003.

MITTOVA, V.; TAL, M.; VOLOKITA, M.; GUY, M. Salt stress induces up-regulation of an efficient chloroplast antioxidant system in the salt-tolerant wild tomato species but not in the cultivated species. Physiologia Plantarum, v.115, n.3, p.393-400, 2002.

MORAES, D. P.; FERNANDES, A. L. M.; DIAS, N. S.; COSME, C. R.; SOUSA NETO, O. N.. Rejeito salino e solução nutritiva em alface cultivada em sistema hidropônico. Magistra, v.26, n.3, p. 357-364, 2014.

OHSE S; DOURADO NETO D; MANFRON PA; SANTOS OS. Qualidade de cultivares de alface produzidas em hidroponia. Scientia Agrícola, v.58, n., p.181-185, 2001.

SANTOS, R. S. S.; DIAS, N. S.; SOUSA NETO, O. N.; GURGEL, M. T. Uso do rejeito da dessalinização de água salobra no cultivo da alface (Lactuca sativa L.) em sistema hidropônico NFT. Ciência e Agrotecnologia, v.34, n.4, p.983-989, 2010.

SILVA, D. R. G.; RODRIGUES, L.; MACEDO, F. S.; CARLOS, L.; VEIGA, A. D.; FAQUIN, V.; SOUZA, M. A. S. Desenvolvimento de cebolinha em cultivo hidropônico em função de doses de boro e zinco. Magistra, v.22, n.1, p.6470, 2010.

SILVA, M. G.; SOARES, T. M.; GHEYI, H. R.; OLIVEIRA, I. S.; SILVA FILHO, J. A. Crescimento e produção de coentro hidropônico sob diferentes densidades de semeadura e diâmetros dos canais de cultivo. Irriga, v. 21, n.2, p. 312-326, 2016.

SOARES, T. M.; SILVA, E. F. F.; DUARTE, S. N.; MELO, R. F.; JORGE, C. A.;BOMFIMSILVA, E. M. Produção de alface utilizando águas salinas em sistema hidropônico. Irriga, v.12, n.2, p.235-248, 2007. 
TAIZ, L.; ZEIGER, E. Plant physiology. 3.ed. Sunderland: Sinauer Associates, 2004. 690p.

TURAZI, C. M. V.; JUNQUEIRA, A. M. R.; OLIVEIRA, S. A. de; BORGO, L. A. Acúmulo de nitrato em alface em função da adubação, horário de colheita e tempo de armazenamento. Horticultura Brasileira, v.24, n.1, p.65-70, 2006.

VIANA, S. B. A.; RODRIGUES, L. N.; FERNANDES, P. D.; GHEYI, H. R. Produção da alface em condições de salinidade a partir de mudas produzidas com e sem estresse salino. Revista Brasileira de Engenharia Agrícola e Ambiental, v.5, n.1, p.60-66, 2001. 